Bio-grafía. Escritos sobre la Biología y su Enseñanza. ISSN 2027-1034

Número Extraordinario. p.p. 262-273

Memorias del Primer encuentro ambiental Universidad, ambiente y sustentabilidad: experiencias y prácticas.

\title{
INCREMENTO DE LOS NIVELES DE COMPRENSIÓN DE LA EDUCACIÓN AMBIENTAL A TRAVÉS DE LA MÚSICA Y SU RELACIÓN EN LA ENSEÑANZA DE LA BIODIVERSIDAD LOCAL
}

\author{
Andrea Catalina Vigoya Ruiz ${ }^{1}$
}

\begin{abstract}
Resumen:
En pleno siglo $X X I$, se debe tener en cuenta que cada persona tiene una manera particular de aprender. Los seres humanos, aprendemos a partir de lo que nuestros sentidos reconocen. Este proyecto se desarrolló en el Colegio Campestre Monteverde con el grado 901, con el fin de fortalecer la comprensión de la educación ambiental involucrando la música en la enseñanza de la biodiversidad local. Se realizó un diagnóstico sobre los conocimientos de los estudiantes acerca de la biodiversidad para reconocer de qué manera se debería implementar la música en su enseñanza y así lograr establecer elementos del proceso de comprensión de la educación ambiental entre la enseñanza tradicional y la integradora ${ }^{2}$. Los datos recolectados se obtuvieron a partir de la observación participante del investigador y del análisis de los diferentes trabajos e informes entregados por parte de los estudiantes.
\end{abstract}

Palabras clave: Educación ambiental, Música, biodiversidad, niveles de comprensión, Biofília.

\begin{abstract}
:
In the XXI century, it must be taken into account that each person has a particular way of learning. Humans, we learn from what our senses recognize. This project was developed at the Colegio Campestre Monteverde with grade 901, in order to strengthen the understanding of environmental education involving music in the teaching of local biodiversity. A diagnosis was made on students' knowledge about biodiversity to recognize how music should be
\end{abstract}

\footnotetext{
${ }^{1}$ Universidad Pedagógica Nacional. Bogotá, Colombia. Estudiante de Licenciatura en Biología. Email: dbi_acvigoyar019@pedagogica.edu.co

${ }^{2}$ La enseñanza integradora hace referencia la implementación de la música en la enseñanza de la educación ambiental, pues allí se trata de entender que la música en la educación general, permite desarrollar competencias que implican destrezas, hábitos, actitudes y conocimientos que mejoran la capacidad de decidir y realizar nuestra propia vida. (Cabedo A. y Arriaga C. 2016)
} 
Bio-grafía. Escritos sobre la Biología y su Enseñanza. ISSN 2027-1034

Número Extraordinario. p.p. 262-273

Memorias del Primer encuentro ambiental Universidad, ambiente y sustentabilidad: experiencias y prácticas.

implemented in their teaching and thus to establish elements of the process of understanding environmental education between traditional and integrative teaching. The data collected were obtained from the participant observation of the researcher and from the analysis of the different works and reports given by the students.

Key words: Environmental education, Music, Biodiversity, levels of understanding, Biophilia.

\section{INTRODUCCIÓN}

Colombia es un país rico en biodiversidad, sin embargo, es uno de los territorios con los recursos naturales más amenazados, debido a que cruza por conflictos de tipo social, y económico que conducen a la pérdida de los ecosistemas (Instituto de Investigación de recursos biológicos Alexander Von Humboldt, 1997). Las contradicciones entre los diferentes objetivos de las políticas frente a lo económico, social y ambiental han generado indirectamente la pérdida de la biodiversidad Colombiana, donde la transformación de los paisajes y la fragmentación de los hábitats son generadas por las diferentes actividades humanas como la deforestación, la agricultura y la construcción de obras civiles, sin embargo, la transformación de los ecosistemas no siempre es total ya que quedan algunos parches de vegetación generando así la fragmentación de los hábitats. Como consecuencia de esto, los efectos que surgen se expresan en dos aspectos: alteraciones de los patrones locales de flujo de materia y energía (cambios en las condiciones físicas que regulan el clima local) y la extinción de las especies (Instituto de Investigación de recursos biológicos Alexander Von Humboldt, 1997).

En adición, la sabana de Bogotá cuenta con diferentes ecosistemas que permiten la proliferación de diferentes formas de vida que tienen un gran valor ecológico y cultural para la población colombiana. Dentro de dichos ecosistemas se encuentra el Páramo, lugar donde se ubica el Colegio Campestre Monteverde I.E.D. el cual, se encuentra ubicado en la localidad 2 de Chapinero, donde confluyen lugares biodiversos como el páramo de Moyas, las quebradas de Puente piedra, Morací y las lajas. Dicho ecosistema es un lugar que está sufriendo disminuciones drásticas de biodiversidad debido a la introducción de ganado, la producción agrícola y principalmente el incremento de urbanización en esta zona, que afecta la flora y fauna particular de este ecosistema, donde los sistemas vivos están siendo seriamente afectados, ya que sus condiciones de vida presentan especializaciones particulares frente a las adaptaciones. Por esta razón este proyecto tiene la intención de 
Bio-grafía. Escritos sobre la Biología y su Enseñanza. ISSN 2027-1034

Número Extraordinario. p.p. 262-273

Memorias del Primer encuentro ambiental Universidad, ambiente y sustentabilidad: experiencias y prácticas.

entrelazar la música y la enseñanza de la biodiversidad Colombiana, para incrementar la comprensión de la educación ambiental, ya que la música hace parte de la vida, tanto para explicar las formas de comunicación entre los diferentes organismos, como para explicar la forma de expresión del ser humano, punto importante al momento de interactuar con los estudiantes, puesto que el fin de este proyecto fue retomar aquellas emociones que vienen de ellos para poder propiciar espacios que contribuyan a la adecuada formación ambiental, incentivando en los estudiantes la generación de propuestas y acciones en pro de la conservación de la biota local.

Este proyecto presentó como objetivo general, el incrementar los niveles de comprensión de la educación ambiental involucrando la música en la enseñanza de la biodiversidad local en estudiantes de grado 901 del Colegio Campestre Monteverde, donde se tuvieron en cuenta los siguientes objetivos específicos: Realizar un diagnóstico sobre los conocimientos de los estudiantes acerca de la biodiversidad; Abordar las temáticas relacionadas con la biodiversidad de una manera tradicional; Abordar las temáticas relacionadas con la biodiversidad involucrando la música en su enseñanza. Finalmente, comparar los niveles de comprensión de la educación ambiental entre la enseñanza tradicional y la enseñanza integradora y fortalecer los procesos de aprendizaje sobre la educación ambiental en temas relacionados con la conservación de la biodiversidad por medio de la música

\section{Planteamiento del problema}

Una de las principales problemáticas de la educación colombiana se viene dando a causa de la falta de interés de los estudiantes por la comprensión de las ciencias, donde el profesorado suele aducir que esta valoración e imagen negativas se da en todas las disciplinas, porque estamos en una sociedad que sólo valora el éxito fácil y no el esfuerzo, pero lo cierto es que esta valoración es más negativa en el caso de las ciencias (Solbes J, et al. (2007)).

No obstante, este desinterés puede generar una falta de comprensión hacia temas que involucren lo ambiental, evitando que los estudiantes promuevan un pensamiento crítico que permita dar posibles soluciones a las problemáticas ambientales que sufre actualmente el país como la pérdida de la biodiversidad, la contaminación de recursos hídricos, el aumento de enfermedades, entre otros. En el colegio Campestre Monteverde, gracias a la contextualización que se realizó se determinó que los niveles de comprensión son bajos, donde los estudiantes se limitan a repetir una acción para poder obtener notas altas, perdiendo así el sentido de comprender aquello que el maestro está enseñando. 
Bio-grafía. Escritos sobre la Biología y su Enseñanza. ISSN 2027-1034

Número Extraordinario. p.p. 262-273

Memorias del Primer encuentro ambiental Universidad, ambiente y sustentabilidad: experiencias y prácticas.

De acuerdo con lo anterior los bajos niveles de comprensión en el colegio son causados por diferentes factores como el consumo de drogas por parte de algunos estudiantes, la desarticulación de la ciencia biológica con otras disciplinas mostrando un carácter aburrido, entre otros. De esta forma, la música juega un papel importante en la mediación del aprendizaje en los estudiantes de grado noveno ya que la música es una forma de expresión integradora y compleja que permite desarrollar diferentes actitudes y aptitudes permitiendo fortalecer la autoestima y otros valores propios del ser humano. Según lo planteado anteriormente surge la siguiente pregunta problema: ¿Cómo incrementar los niveles de comprensión de la educación ambiental involucrando a la música en la enseñanza de la biodiversidad local en estudiantes de grado 901 de Colegio Campestre Monteverde?

\section{MARCO TEÓRICO}

En Colombia se llevan a cabo diferentes maneras de abordar la educación ambiental en las escuelas, lo cual se hace importante, ya que este permite modificar de manera significativa las actitudes y aptitudes de las personas, por esta razón, la educación ambiental se convierte en un proceso que reconoce valores y aclara los conceptos centrados en fomentar actitudes, destrezas, habilidades y aptitudes necesarias para apreciar las interrelaciones entre el ser humano, su cultura y la naturaleza (Rengifo B. y colaboradores 2012).

De esta manera, Rengifo y colaboradores (2012) asume que la educación ambiental pretende enseñar algo a alguien que quiere aprender y para esto, necesita mostrar caminos, insinuar horizontes teniendo en cuenta preguntas sobre los contenidos teóricos y prácticos a trabajar desde lo ambiental, ubicados en un entorno y en una cultura específica, por esta razón, la educación musical es un aspecto fundamental para promover la formación integral de la personalidad, pues su práctica requiere la participación de planos sensoriales, afectivo-mental, corporal y social. Sin embargo, en la escuela se ha venido perdiendo un sentido frente a lo que tiene que ver con la música, los maestros deben incursionar en otras áreas facilitando el trabajo interdisciplinar, como lo menciona Neuman V.:

... Estos deben incursionar en otras áreas y facilitar que éstas incursionen en la música, y lograr que su tarea facilite el trabajo interdisciplinar, obstaculizado en la práctica por la "balcanización" de los profesores (Hargreaves, 1996), dado que "se ha restringido gravemente la colaboración entre áreas de conocimiento diferentes, provocando la incoherencia pedagógica, una territorialidad competitiva y la falta de oportunidades para que unos profesores aprendan de otros y se brinden mutuo apoyo" 
Bio-grafía. Escritos sobre la Biología y su Enseñanza. ISSN 2027-1034

Número Extraordinario. p.p. 262-273

Memorias del Primer encuentro ambiental Universidad, ambiente y sustentabilidad: experiencias y prácticas.

Paralelo a esto, la enseñanza de la biodiversidad colombiana toma gran relevancia para fomentar esos valores de los que habla Rengifo B. et al., donde se habla de ella como la variabilidad de los organismos vivos de cualquier origen, incluidos, entre otras cosas, los ecosistemas terrestres, marinos y otros ecosistemas acuáticos, y los complejos ecológicos de los que forman parte; comprende la diversidad dentro de cada especie, entre las especies y de los ecosistemas (Convenio de Naciones Unidas sobre Conservación y Uso Sostenible de la Diversidad Biológica). Atendiendo a la importancia de los vínculos emocionales que surgen de los seres humanos hacia la naturaleza y la influencia que tienen estos sentimientos hacia la conservación de la biodiversidad, Sánchez M. y De la Garza A. (2015) citan a Edward O. Wilson (1989) quien plantea que la biofilia es la tendencia de los seres humanos a sentirse identificados con la naturaleza, según el autor esta tiene un origen genético que es causado por nuestra evolución en los diferentes espacios naturales. Así mismo, tiene un valor adaptativo que nos ha permitido desarrollarnos y sobrevivir en el entorno.

\section{METODOLOGÍA}

Este trabajo, se desarrolló teniendo en cuenta un paradigma cualitativo que permite que los individuos interactúen con otros miembros del contexto social, compartiendo así el significado y conocimiento que tienen sobre sí mismos y sobre su realidad (Bonilla y Castro, 1989). No obstante, durante la primera sesión se utilizó la investigación cuantitativa utilizado en menor medida que el enfoque cualitativo, pues solamente aportó a la realización de la primera sesión para determinar los conocimientos que traen los estudiantes acerca de la biodiversidad y la biodiversidad local. Se realizó la recolección de datos a partir de métodos como la observación participante apoyados sobre en instrumentos que permiten obtener mayor información del contexto, como la entrevista, las encuestas, grabadoras, cámaras, cuaderno y diario de campo.

No obstante, el desarrollo de la propuesta de investigación se llevó a cabo en dos fases:

Fase I: Esta fase, se llevó a cabo en la práctica 1, donde se realizó el primer acercamiento a la escuela, en este caso al Colegio Campestre Monteverde.

Fase II: Se realizó la implementación de la propuesta de investigación abordada en la práctica I.

\section{RESULTADOS Y ANÁLISIS}

A continuación, se presentarán los resultados y análisis iniciales que se llevaron a cabo en el presente estudio. Cabe resaltar que aún se están 
Bio-grafía. Escritos sobre la Biología y su Enseñanza. ISSN 2027-1034

Número Extraordinario. p.p. 262-273

Memorias del Primer encuentro ambiental Universidad, ambiente y sustentabilidad: experiencias y prácticas.

llevando a cabo otras sesiones que involucran aspectos musicales con los estudiantes.

Fase II:

Momento I: Explicación teórica sobre la biodiversidad.

- Sesión 1: En esta sesión se llevó a cabo la realización de una encuesta, que permitió recolectar datos acerca de los conocimientos previos de los estudiantes sobre el tema de la biodiversidad.
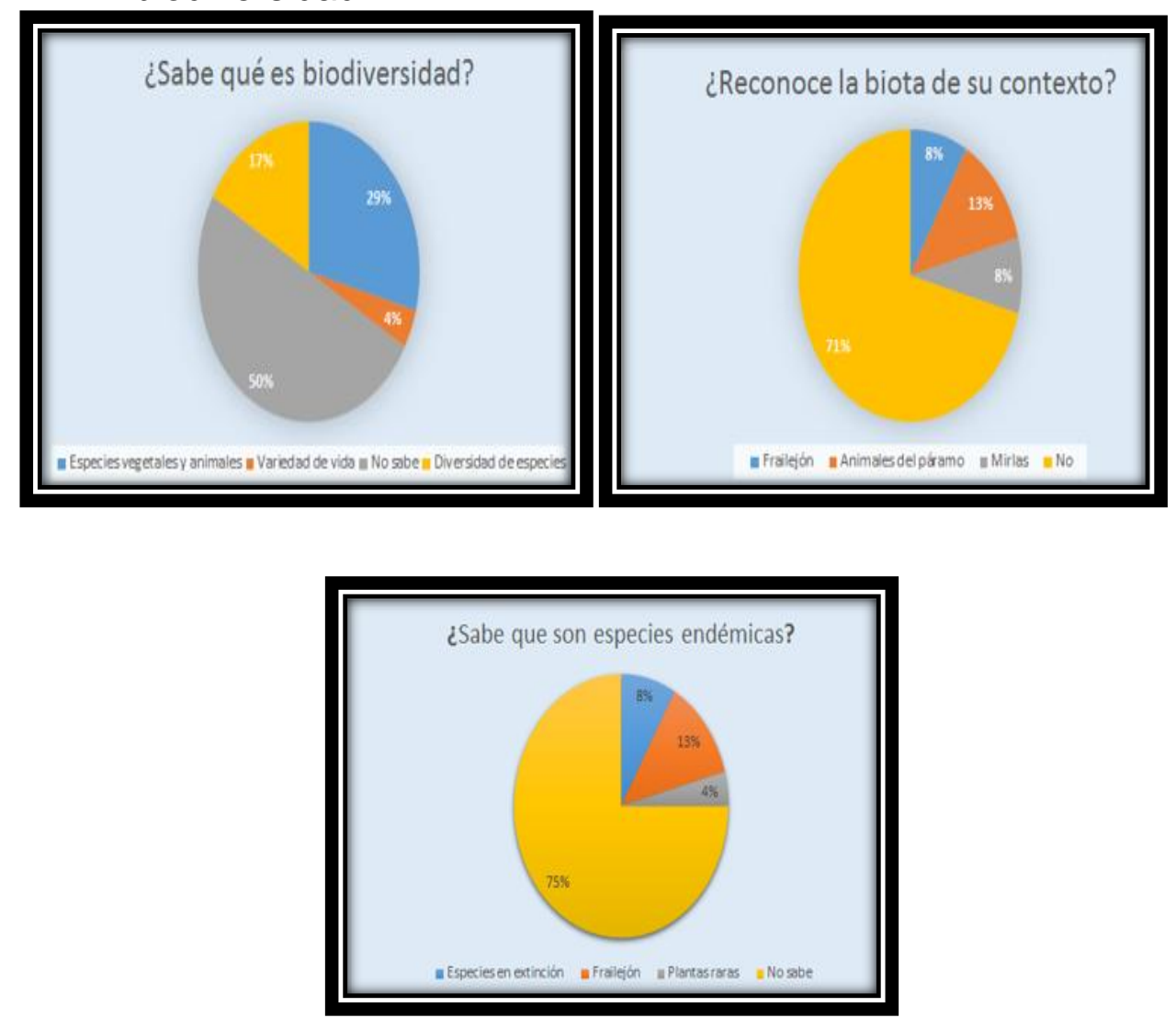

Figura II: Gráficas estadísticas sobre los conocimientos previos de los estudiantes acerca del tema de biodiversidad.

Como se puede observar, el $50 \%$ de los estudiantes tienen un desconocimiento total hacia lo que significa la biodiversidad, mientras que el $50 \%$ restante, tiene un desconocimiento parcial del término. En este primer punto, se puede determinar gracias a las respuestas que se obtuvieron, que solamente el $4 \%$ de los estudiantes reconoce que los diferentes reinos hacen parte del conjunto que caracteriza la biodiversidad, mientras que el resto de estudiantes asimilan esta palabra solamente con los reinos animal y vegetal. De acuerdo con esto, se puede inferir que el conocimiento que tienen los estudiantes respecto al tema es fragmentado, pues ignoran las relaciones que puedan ocurrir 
Bio-grafía. Escritos sobre la Biología y su Enseñanza. ISSN 2027-1034

Número Extraordinario. p.p. 262-273

Memorias del Primer encuentro ambiental Universidad, ambiente y sustentabilidad: experiencias y prácticas.

entre los factores bióticos y abióticos propios de la biodiversidad. En esta medida, las afirmaciones que se establecen en torno al término biodiversidad están direccionadas a definirlo como esas variedades de plantas y animales que se encuentran en un ecosistema, olvidando que los grupos sociales también hacen parte de la biodiversidad.

En esta medida, el reconocimiento de la biodiversidad en el territorio colombiano es clave a la hora de conservar las especies y mitigar los daños producidos por el hombre sobre los ecosistemas, trayendo como consecuencia la apropiación del territorio generando un mayor proceso de cuidado y conservación. El territorio no es solamente una fracción de tierra que contiene una serie de organismos vivos, sino que este tiene una estrecha relación con el ser humano. Así, en el territorio se podrán observar integraciones, relaciones, interacciones culturales con el ambiente, donde la problemática ambiental adquiere un carácter específico, producto de la complejidad de los procesos sociales (Sosa M. (2012).

Por otra parte, el reconocimiento de las especies endémicas cumple un papel fundamental para Colombia, pues estos organismos cumplen papeles ecológicos muy importantes para el funcionamiento de los ecosistemas en los que habita. Allí se destacó la importancia de enseñar sobre especies endémicas del país, ya que el desconocimiento por parte de los estudiantes es bastante grande siendo una fracción del $75 \%$ quien desconoce el término, mientras que el otro $25 \%$ relacionan esta palabra como aquellas especies que se encuentran en extinción, plantas raras o frailejones. Como se menciona anteriormente, esta importancia se hace relevante, ya que las condiciones ecológicas que requieren las especies endémicas tienen determinadas especializaciones hacia hábitats particulares los cuales están siendo degradados por el ser humano; es importante tener en cuenta las diferentes relaciones ecológicas ya que estos permiten permite dilucidar los estados de conservación del ecosistema y como las especies se van adaptando a las presiones antrópicas (Novoa M. 2014).

- Sesión 2: "Explorando con los sentidos"

El ejercicio de exploración de los sentidos a partir de la simulación de diferentes sonidos de la naturaleza por parte de los estudiantes, permitió incentivar en ellos curiosidad por entender las formas en que se expresa la naturaleza, pues en un trabajo realizado en clase un estudiante responde:

"Me sentí con mucha curiosidad por ver como los verdaderos animales reaccionan”. Javier Caita. Estudiante de grado 901. 
Bio-grafía. Escritos sobre la Biología y su Enseñanza. ISSN 2027-1034

Número Extraordinario. p.p. 262-273

Memorias del Primer encuentro ambiental Universidad, ambiente y sustentabilidad: experiencias y prácticas.

De acuerdo con este resultado, es importante que en la escuela se enseñe que los seres humanos mantienen una relación estrecha con la naturaleza, pues si se observa, el estudiante menciona la curiosidad que tiene por observar las dinámicas presentes en "los verdaderos animales" ignorando el hecho de que nosotros como seres humanos también pertenecemos al reino animal. A partir de esto se rescata que nosotros como organismos vivos, nos desarrollamos en ambientes biodiversos, donde aún se mantiene afinidad con los ecosistemas en los cuales nos desarrollamos, según esto, E. O. Wilson destaca que "nuestra biofilia es innata, un producto evolutivo de la selección natural que actúa en especies inteligentes, cuya supervivencia depende de la conexión estrecha con el ambiente y de la apreciación práctica de las plantas y animales". No obstante, la biofilia permite establecer una ética ambiental entre los individuos y las sociedades (Campbell N. 2007).

Además, la actividad tuvo que ser suspendida y proceder al salón de clase, ya que algunos de los estudiantes no se encontraban en la mejor disposición para realizarla, por un lado, unos cuantos estudiantes al ver a sus compañeros con los ojos vendados aprovechaban para realizar bromas dándoles golpes en la cabeza, mientras que otros estudiantes no se vendaron los ojos ya que les daba pena realizar la actividad. En el salón de clase los estudiantes se mostraron con muchas distracciones, enseñarles sobre biodiversidad en un tablero donde no existe mucha interacción con esa biodiversidad local es algo ilógico cuando viven en un ecosistema en donde perfectamente se puede aprender acerca de lo que es biodiversidad, pues aprender Biología en el campo, permite observar los fenómenos naturales directamente, aplicando los conceptos trabajados en el aula a partir de modelos de la realidad (Pedrinaci et al. 1994 (citado en Rodríguez C. y Amórtegui E. 2012)).

\section{- Sesión 3, 4 y 5:}

Estas sesiones permitieron determinar cuál es la capacidad de comprensión de la educación ambiental por parte de los estudiantes, abordada desde temáticas como la biodiversidad donde se muestra implícitamente dando a conocer las problemáticas ambientales, sociales, económicas, entre otras problemáticas propias del contexto. Allí, como resultado se obtuvo, que los estudiantes reconocen que el término biodiversidad hace alusión a la variedad y variabilidad de organismos presentes en un ecosistema, sin embargo, se quedan cortos a la hora de evidenciar que el ambiente del cual están rodeados, tiene un significado que va mucho más allá de la realidad objetiva; no reconocen que este ambiente ha sido una construcción social, que implica una interacción sujeto-sujeto-objeto que juega un rol importante para poder transformar las prácticas que afectan los ecosistemas. 
Bio-grafía. Escritos sobre la Biología y su Enseñanza. ISSN 2027-1034

Número Extraordinario. p.p. 262-273

Memorias del Primer encuentro ambiental Universidad, ambiente y sustentabilidad: experiencias y prácticas.

La evaluación grupal dio cuenta de que los estudiantes discuten y reflexionan frente a lo que se está planteando; análogamente prestan atención a las respuestas que dan sus compañeros para opinar si aquello que dice está bien o mal. Este tipo de evaluación acepta que el trabajo mancomunado sea adecuado para fomentar la crítica constructiva y reflexiva, ya que los estudiantes están dispuestos a considerar las opiniones de los demás para aportar de manera significativa de acuerdo a lo que se pregunta. Cabe resaltar, que los estudiantes dieron respuestas donde problematizan las acciones de los seres humanos sobre la biodiversidad.

Por otra parte, la evaluación escrita es oblicua, en el sentido en que permite conocer de qué manera cada uno de los estudiantes interpreta las preguntas formuladas, pero dificulta la capacidad de reflexión asociada a otros puntos de vista, sin embargo, es un reto pedagógico sobre el cual el profesor debe reflexionar, ya que este es quien debe tomar una postura sobre la manera en que evidencia la comprensión de los temas abordados por parte de los estudiantes. En este sentido, Popkewitz T. (1992) menciona que:

la evaluación necesita centrarse no sólo en los supuestos fundamentales sobre los objetivos de la escolarización que subyacen en la práctica, sino también en las cuestiones referentes a la relación entre el individuo y la sociedad que se da en las construcciones pedagógicas. La evaluación debe proporcionar un discurso sobre la educación que examine los modos en que la escuela ilumina u oculta las condiciones sociales en las que vive la gente.

Momento II: Explicación teórico práctica.

\section{- Sesión 6:}

En esta sesión se pudo evidenciar que la música permite generar sentimientos biofílicos que abogan por el cuidado de la naturaleza. La música incita diferentes tipos de ánimo los cuales tienen consecuencias en tareas psicomotoras y cognitivas. Los estudiantes al escuchar ritmos musicales como el Swing Jazz asociado a imágenes de la biota colombiana generan sensaciones de bienestar, donde reconocen intrínsecamente el valor estético de la biodiversidad. Esta incidencia sobre el estado de ánimo se debe a que la música actúa directamente en el sistema nervioso central aumentando, en este caso, los niveles de endorfinas y otros neurotransmisores como la acetilcolina, oxitocina y dopamina, donde se ha descubierto que las endorfinas provocan alegría y optimismo (Oxestein, S. 2008). Por otra parte, el Blues y la música clásica generan sentimientos de angustia, tristeza, depresión, entre otros, los cuales generaron en los estudiantes la necesidad de contribuir con el 
Bio-grafía. Escritos sobre la Biología y su Enseñanza. ISSN 2027-1034

Número Extraordinario. p.p. 262-273

Memorias del Primer encuentro ambiental Universidad, ambiente y sustentabilidad: experiencias y prácticas.

cuidado del medio ambiente generando en ellos la iniciativa de construir cartas a sus compañeros que demostraron un compromiso con el medio ambiente.

\section{- Sesión 7:}

Consistió en la clasificación taxonómica a nivel de clase de los diferentes organismos a partir de los sonidos producidos por la naturaleza. Este momento sirvió para darse cuenta de retos que debe asumir el maestro, pues si bien, se tenía planteado realizar una clase donde reconocieran los sonidos de la naturaleza, los estudiantes mostraron indiferencia ante la actividad ya que no están acostumbrados a otras formas de enseñanza produciendo así que la clase se tornara de manera que se utilizara el tablero para abordar la temática.

\section{- Sesión 8 y 9 :}

Se llevó a cabo la visita al páramo de las Moyas para realizar el reconocimiento de la biodiversidad a partir de los sonidos que se percibían y la realización de organismos que presentaran esas características de realizar sonidos con alguna parte de su cuerpo. Gracias a la visita al páramo y la caracterización de la biodiversidad a partir de los sonidos, se pudo determinar junto con los estudiantes que existen diferentes maneras de abordar la temática de la biodiversidad, desde el reconocimiento a partir de la escucha hasta el reconocimiento a partir de la utilización de parcelas para realizar el análisis de datos a partir de datos estadísticos. Además, el instituto de Investigación Alexander Von Humboldt (2014) sostiene que el conjunto de los sonidos de la naturaleza es una fuente de información que refleja la diversidad, el funcionamiento y la complejidad de los sistemas ecológicos. Su estudio permite abarcar diferentes niveles de organización: individuos, poblaciones, ensambles y paisajes.

\section{CONCLUSIONES}

Si bien, Colombia es un país mega diverso, la falta de conocimiento hacia los temas como la biodiversidad hacen que exista una pérdida constante de la misma, pues es una realidad que en las escuelas los estudiantes presentan vacíos a la hora de abordar temas referentes a la biodiversidad propia del país. Por esta razón, los maestros colombianos, deben asumir la tarea de profundizar sobre esta temática ya que la biodiversidad es importante porque constituye el sostén de una gran variedad de servicios ambientales de los cuales han dependido las sociedades humanas; por ejemplo, proporciona bienes para las necesidades fundamentales: alimentación, tejidos, medicinas, alojamiento y combustible (Andrade M. 2011). 
Bio-grafía. Escritos sobre la Biología y su Enseñanza. ISSN 2027-1034

Número Extraordinario. p.p. 262-273

Memorias del Primer encuentro ambiental Universidad, ambiente y sustentabilidad: experiencias y prácticas.

La articulación de la música con la enseñanza de la biodiversidad, permitió generar en ellos reflexiones en torno a las problemáticas ambientales que surgen en el país, donde lograron a través de la visita al páramo y del ejercicio de escucha, reconocer que la población humana hace parte de la naturaleza, en el cual, las acciones humanas pueden contribuir o por el contrario truncar las relaciones ecológicas que se presentan en cada uno de los ecosistemas.

Por otra parte, intentar articular las diferentes áreas del conocimiento, en este caso, la música y la educación ambiental, es un reto, tanto para el maestro como para el estudiante, ya que el maestro debe incentivar a que el estudiante realmente sienta pasión por aquello que está aprendiendo, análogamente, el estudiante debe dejar de lado los esquemas mentales que asumen que se debe enseñar ciencias de una manera metódica y procedimental, donde se conocen solamente de manera abstracta y memorística.

\section{REFERENCIAS BIBLIOGRÁFICAS:}

Andrade M. (2011). Estado del conocimiento de la biodiversidad en Colombia y sus amenazas. consideraciones para fortalecer la interacción ciencia-política. Rev. Acad. Colomb. Cienc. 35 (137): 491-507, ISNN 0370-3908

Campbell N. \& Reece J. (2005). Biología: Biofília y el futuro de la biósfera. p.p. 1229. España. Copyright.

Fundación Española para la Ciencia y la Tecnología (FECYT) (2011). Biodiversidad: El mosaico de la vida. Madrid, España. En: file://C:/Users/Catalina/Downloads/491929281.pdf

Gómez M. \& Polanía N. (2008). ESTILOS DE ENSEÑANZA Y MODELOS PEDAGÓGICOS: Un estudio con profesores del Programa de Ingeniería Financiera de la Universidad Piloto de Colombia. Bogotá, Colombia. En: http://repository.lasalle.edu.co/bitstream/handle/10185/1667/T85.08\%20G 586e.pdf;jsessionid=B8870679E47248E7C096518C44606D3C?sequence $=1$

Instituto de Investigación de Recursos Biológicos Alexander von Humboldt. (2014). Primer Curso de Caracterización y Monitoreo Bioacústico en Colombia (4-16/08/2014). Colombia. En: http://humboldt.org.co/es/noticias/actualidad/item/473-curso-bioacusticocolombia 
Bio-grafía. Escritos sobre la Biología y su Enseñanza. ISSN 2027-1034

Número Extraordinario. p.p. 262-273

Memorias del Primer encuentro ambiental Universidad, ambiente y sustentabilidad: experiencias y prácticas.

Novoa M. (2014). Monitoreo de las especies endémicas amenazadas tingua bogotana Rallus semiplumbeus y el cucarachero de pantano Cistothorus apolinari en el tercio alto del humedal juan amarillo distrito capital. Bogotá, Colombia.

En: http://repository.unimilitar.edu.co/bitstream/10654/12014/1/Articulo\%20tes is\%20de\%20grado-Humedales.pdf

Oxenstein S. (2008). El impacto de la música en las emociones. Lima, Perú. $\quad$ En: http://adpps.com/descargas/trabajos/001EllmpactoDeLaMusicaEnLasEmociones-SaraOxenstein.pdf

Peñalver, J. (2010). ¿Cuál debe ser la función de la música con relación a la imagen? Una experiencia docente con estudiantes de la licenciatura en Comunicación Audiovisual. Sonograma. Revista de pensament musical núm. 006.

Popkewitz T. (1992). Algunos problemas y problemáticas en la producción de la evaluación. Universidad de Wisconsin-Madison. Revista de Educación. núm. 299 119921, págs. 95118.

Rengifo B. et al. (2012). La educación ambiental una estrategia pedagógica que contribuye a la solución de la problemática ambiental en Colombia. En: http://www.ub.edu/geocrit/coloquio2012/actas/06-BRengifo.pdf

Solbes, J. et al. (2007). El desinterés del alumnado hacia el aprendizaje de la ciencia: implicaciones en su enseñanza. Departamento de Didáctica de las Ciencias Experimentales y Sociales. Universitat de ValènciaEspaña.

Sosa M. (2012). ¿Cómo entender el territorio? Guatemala. Editorial Cara Parens de la Universidad Rafael Landívar.

Torres J. (2009). La música como ciencia. Mérida. Revista de arte y estética contemporánea. En: http://www.saber.ula.ve/bitstream/123456789/30943/1/articulo10.pdf 